\title{
Muscle Spasms after Thyroidectomy: What Went Wrong?
}

\author{
Mark J Heidenreich, Ryan M Antiel, Diana S Dean, David R Farley
}

\begin{abstract}
Postoperative complications of thyroid surgery are generally limited, though not entirely rare. Cervical hematoma, recurrent laryngeal nerve damage and hypoparathyroidism are of greatest concern, with the latter being the most frequently encountered. We report a case of a Graves thyroid patient who experienced symptomatic hypocalcemia in a post-thyroidectomy setting. Episodes of paresthesia and tetany delayed the patient's hospital discharge, serving as a reminder of the potential morbidities thyroid surgery can entail.
\end{abstract}

Keywords: Thyroidectomy, Hypocalcemia, Tetany.

How to cite this article: Heidenreich MJ, Antiel RM, Dean DS Farley DR. Muscle Spasms after Thyroidectomy: What Went Wrong? World J Endoc Surg 2013;5(1):16-17.

\section{Source of support: Nil}

\section{Conflict of interest: None}

\section{CLINICAL SCENARIO}

A 26-year-old male presented to the Mayo Clinic Rochester with a 6-month history of progressive tremor. The tremor had advanced such that he now had difficulty writing his name and buttoning his shirt. He reported increased perspiration, heat intolerance, fatigue, agitation, restlessness, poor concentration, difficulty sleeping, shortness of breath and palpitations upon exertion. In addition, he had experienced an unintentional 30-pound weight loss over the past year. There was a significant family history for autoimmune thyroid failure.

On physical exam, his thyroid gland was visible and palpable with an estimated size of $50 \mathrm{gm}$. There was no focal nodularity. Laboratory tests revealed a completely suppressed thyroid-stimulating hormone (TSH; $<0.010 \mathrm{mIU} / \mathrm{l}$ ) and a free thyroxine of $8.1 \mathrm{ng} / \mathrm{dl}$ (normal: 0.8-1.8 ng/dl). The patient was diagnosed with Graves disease and started on propanol and propylthiouracil. Two months later his free thyroxine normalized $(1.3 \mathrm{ng} / \mathrm{dl})$, however, his TSH remained suppressed $(<0.010 \mathrm{mIU} / \mathrm{l})$. Given the severity of his symptoms, long-term anti-thyroid management was not ideal and definitive treatment was pursued. The patient opted for surgery over radioactive iodine therapy.

A total thyroidectomy was performed. The 'woody' nature of the thyroid tissue and a prominent tubercle of Zuckerkandl made dissection particularly difficult around the recurrent laryngeal nerves; extra care was taken to preserve the parathyroid glands of their blood supply (Fig. 1). No viable thyroid tissue was left within the neck. Pathologic analysis revealed enlarged thyroid lobes: Right
$=20.5 \mathrm{gm}$ and left $=28.3 \mathrm{gm}$. Histologic analysis revealed bilateral lymphocytic thyroiditis with hyperplasia (Fig. 2).

The patient tolerated the procedure well and was started on the standard postoperative management of oral calcium and vitamin D. However, on postoperative day 2, the patient began to experience muscle spasms, perioral numbness and episodes of warmth over his body. Laboratory tests revealed a serum calcium of $7.1 \mathrm{mg} / \mathrm{dl}$ and parathyroid hormone (PTH) of $<0.2 \mathrm{pmol} / \mathrm{l}$. We initiated intravenous $10 \%$ calcium gluconate. Electrocardiography revealed a normal QTc interval. On postoperative day 3 , his serum calcium level continued to decline and reached a low of $6.5 \mathrm{mg} / \mathrm{dl}$. His PTH remained at $<0.2 \mathrm{pmol} / \mathrm{l}$. Continued intravenous calcium therapy was required to avert tetany. After 13 postoperative days of monitoring and aggressive calcium supplementation, his serum calcium level was measured at $9.3 \mathrm{mg} / \mathrm{dl}$ and his PTH measured at $0.9 \mathrm{pmol} / \mathrm{l}$. The patient was discharged on calcium citrate, calcium acetate, calcitriol and hydrochlorothiazide in addition to levothyroxine. Over the next 6 months his calcium and PTH values normalized and we terminated his calcium supplementation.

\section{DISCUSSION}

Each year, more than 50,000 thyroidectomies are performed in the United States. ${ }^{1}$ Indications for thyroidectomy include treatment for both benign and malignant thyroid lesions. Depending on the indication, patients may undergo thyroid nodulectomy, partial thyroidectomy, lobectomy, subtotal thyroidectomy, near total thyroidectomy or total thyroidectomy. ${ }^{2}$ Recent studies have highlighted the growing popularity of total thyroidectomy as definitive treatment for benign thyroid disease, with one study noting an average annual increase in the procedure of $8.2 \%$ in the United

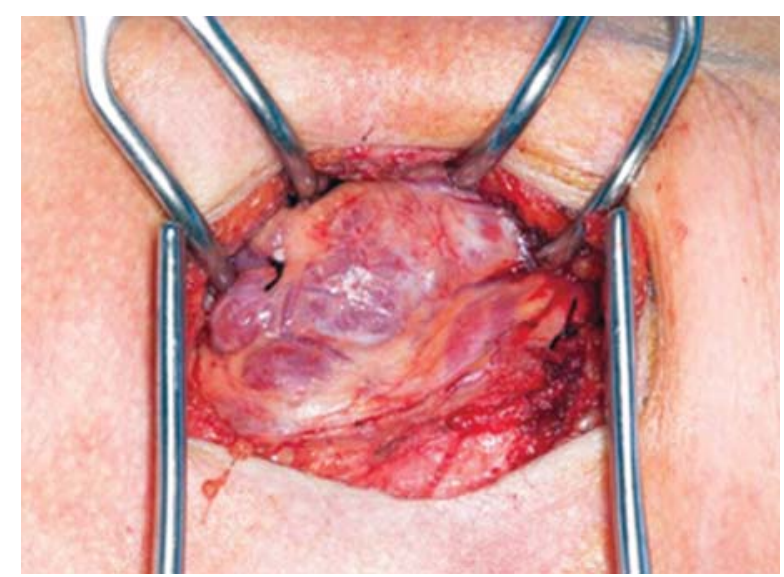

Fig. 1: Intraoperative view of nodular, 'woody' thyroid gland of Graves' patient 
States. ${ }^{3}$ With regard to Graves disease, total and near total thyroidectomy are definitive treatment options for patients unresponsive to medical management with thionamides or radioiodine ablation.

In general, thyroid surgery has a very safe profile, rarely involving serious postoperative morbidity. Hematoma, recurrent laryngeal nerve injury, and hypoparathyroidism are potential complications of thyroid surgery. ${ }^{4}$ Hypoparathyroidism is the most common complication following total thyroidectomy, with permanent hypoparathyroidism occurring in $4.4 \%$ of cases and transient hypoparathyroidism occurring in $10 \%$ of cases. ${ }^{5}$

Postoperative transient hypoparathyroidism results in hypocalcemia. Parathyroid hormone maintains the serum calcium level by indirectly stimulating osteoclasts, enhancing distal tubule calcium reabsorption and activating the renal production of calcitriol $\left(1,25-(\mathrm{OH})_{2} \mathrm{D}\right)$, which increases calcium absorption in the gut. ${ }^{6}$ The hallmark symptom of hypocalcemia is tetany, which can manifest as numbness, paresthesias, muscle cramping or seizure activity. ${ }^{7}$ Hypocalcemia after thyroid surgery is most often caused by physical damage, devascularization or inadvertent removal of the parathyroid glands during surgery. Other causes, independent of parathyroid hormone levels, include a rise in calcitonin hormone secondary to thyroid mobilization during surgery or hemodilution resulting from intraoperative fluid administration. ${ }^{4}$ Finally, transient hypocalcemia in thyrotoxic patients may result from 'hungry bone syndrome', in which thyroidectomy reverses thyrotoxic osteodystrophy resulting in a drop in serum calcium. ${ }^{5}$ Patients with Graves disease are particularly notorious for problems with hypocalcemia in the early postoperative period.

Treatment of transient postoperative hypocalcemia depends on symptom severity and the underlying function of viable parathyroid tissue. While broad recommendations are not absolute, we suggest patients with serum calcium levels between 7.5 and $8.0 \mathrm{mg} / \mathrm{dl}$ should be started on oral

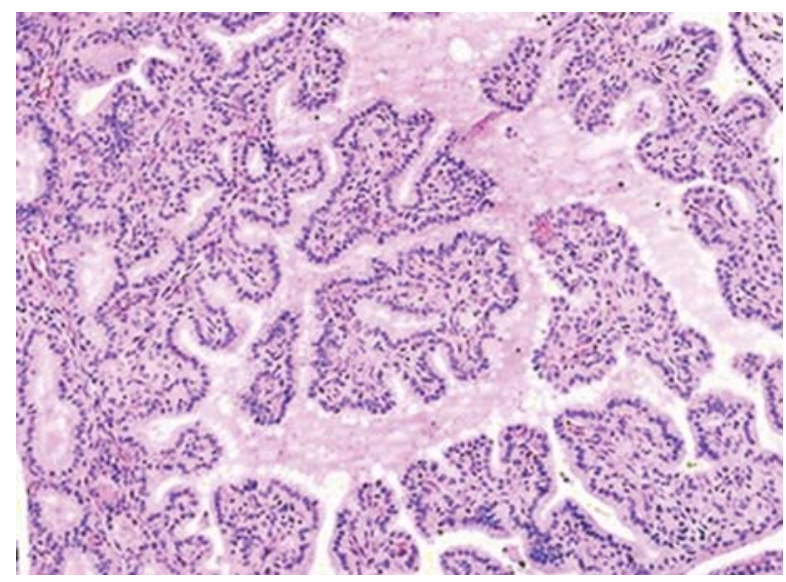

Fig. 2: Hematoxylin and eosin-stained section of a Graves' thyroid replacement, whereas patients with a calcium level between 7.0 and 7.5 should also receive vitamin D supplementation. Calcium levels less than 7.0 typically prompt administration of intravenous calcium in addition to oral calcium and vitamin D. ${ }^{4}$ Furthermore, the use of synthetic human parathyroid hormone 1-34 in a hypocalcemic setting is gaining interest. ${ }^{8}$ For patients with Graves disease, preoperative usage of both oral calcium and vitamin $\mathrm{D}$ supplementation are gaining favor to preemptively treat what is often a difficult and common postoperative problem. ${ }^{5}$

\section{REFERENCES}

1. Landry CS, Grubbs EG, Hernandez M, et al. Predictable criteria for selective, rather than routine, calcium supplementation following thyroidectomy. Arch Surg 2012;147(4):338-44.

2. Oertli D. Technique of thyroidectomy. In: Oertli D, Udelsman R (Eds). Surgery of the thyroid and parathyroid glands. Berlin, Heidelberg, New York: Springer 2007;81-89.

3. Ho TW, Shaheen AA, Dixon E, Harvey A. Utilization of thyroidectomy for benign disease in the United States: A 15year population-based study. Am J Surg 2011;201(5):570-74.

4. Jameson MJ, Levine PA. Complications of thyroid surgery. In: Terris DJ, Gourin CG (Eds). Thyroid and parathyroid diseases. New York, Stuttgart: Thieme 2009;247-52.

5. Khan MI, Waguespack SG, Hu MI. Medical management of postsurgical hypoparathyroidism. Endocr Pract 2011;17 (Suppl 1):18-25.

6. Holt EH, Inzucchi SE. Physiology and pathophysiology of the parathyroid glands and preoperative evaluation. In: Oertli D, Udelsman R (Eds). Surgery of the thyroid and parathyroid glands. Berlin, Heidelberg, New York: Springer 2007;235-43.

7. Frilling A, Weber F. Complications in thyroid and parathyroid surgery. In: Oertli D, Udelsman R (Eds). Surgery of the thyroid and parathyroid glands. Berlin, Heidelberg, New York: Springer 2007;217-24.

8. Winer KK, Zhang B, Shrader JA, et al. Synthetic human parathyroid hormone 1-34 replacement therapy: A randomized crossover trial comparing pump versus injections in the treatment of chronic hypoparathyroidism. J Clin Endocrinol Metab 2012;97(2):391-99.

\section{ABOUT THE AUTHORS}

\section{Mark J Heidenreich}

Medical Student, Mayo Medical School, Rochester, Minnesota, USA

\section{Ryan M Antiel}

Resident, Department of Surgery, College of Medicine, Mayo Clinic Rochester, Minnesota, USA

\section{Diana S Dean}

Endocrinologist, Department of Endocrinology, College of Medicine Mayo Clinic, Rochester, Minnesota, USA

\section{David R Farley (Corresponding Author)}

Surgeon, Department of Surgery, College of Medicine, Mayo Clinic Rochester, Minnesota, USA, e-mail: farley.david@mayo.edu 